\title{
Development of Strength and Yield Criteria Based on the Relationship between Elastic and Plastic Strains
}

\author{
Y. Li \\ School of Civil Engineering, Central South University, Changsha, China \\ yli@csu.edu.cn
}

УДК 539.4

\section{Разработка критериев прочности и пластического течения, основанных на соотношениях между упругими и пластическими деформациями}

Ю. Ли

Высшая школа гражданского строительства, Центральный Южный Университет, Чанша, Китай

Представлены результаты исследования соотнотений между упругими и пластическими деформациями. На основании результатов анализа этих соотношений предложен критерий прочности, который является модификацией критерия максимальных главных деформаций. Поскольку предложенный подход увязывает критерии прочности и пластического течения, данный критерий можно трактовать как новый критерий пластического течения.

Ключевые слова: критерий прочности, критерий пластического течения, упругая и пластическая деформации.

Introduction. Strength and yield criteria developments are two important research directions. A relatively comprehensive introduction on their development was made in books written by Patnaik and $\mathrm{Yu}[1,2]$. So far, although many strength and yield criteria have been presented, they have their respective limitations, and can't fully explain the phenomena of yield and failure of materials. That is why these fields are still the hot spot of research for scholars of different countries, and material strength and yield criteria are in the process of constant development and improvement. Recent works [3-11] describe the current situation in this domain. On the other hand, since it is problematic to determine the yield surface under various loading conditions, the research on yield criteria is more difficult than that on strength ones. Moreover, strength and yield criteria are often controlled by similar equations, and it is somewhat difficult to distinguish them strictly. Based on a new direction - the study of relationship between the elastic and plastic parts of strain - a new strength (or yield) criterion are proposed in this paper, and the relationship between strength and yield criteria is discussed for better insight into this domain.

1. Preliminary Results on Relationship Between Elastic and Plastic Strain. According to unloading path, the strain of every point on stress-strain curve in Fig. 1 can be divided into elastic strain $\varepsilon^{e}$ and plastic strain $\varepsilon^{p}$, then $\varepsilon^{e} \sim \varepsilon^{p}$ curve is as in Fig. 2. For brevity, the $\varepsilon^{e} \sim \varepsilon^{p}$ curve is called the $e-p$ curve [12].

As an example, the experiment made by Lessels and MacGregor [13] is considered, where 5 nickel-chrome-molybdenum alloyed steel specimens in the form of thin-walled tubes where tested under different combinations of internal pressures and axial forces, and 2 curves for each specimens were plotted: the axial stress-strain curve and the transverse 


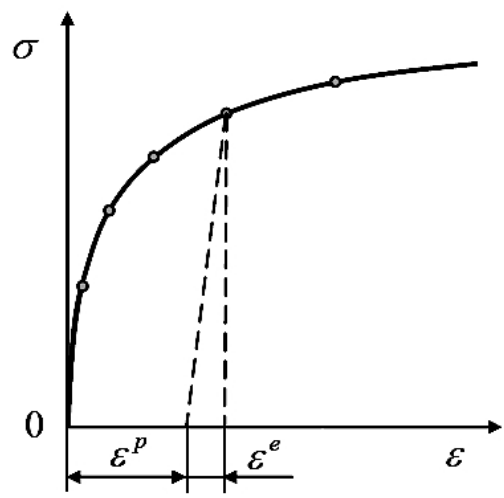

Fig. 1. $\sigma \sim \varepsilon$ curve.

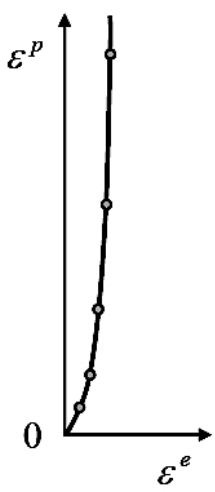

Fig. 2. $e-p$ curve.

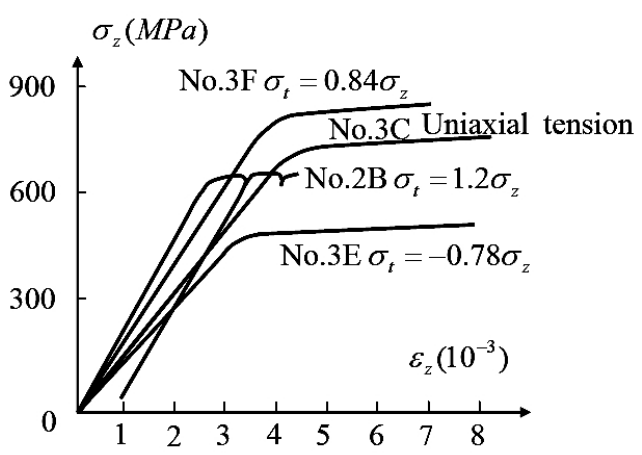

Fig. 3. $\sigma_{z} \sim \varepsilon_{z}$ curve under combined loads.



Fig. 5. $e-p$ curve from Fig. 3 .

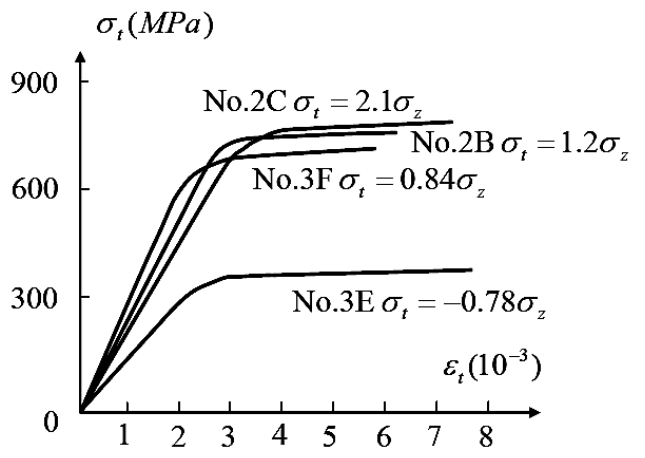

Fig. 4. $\sigma_{t} \sim \varepsilon_{t}$ curve under combined loads.

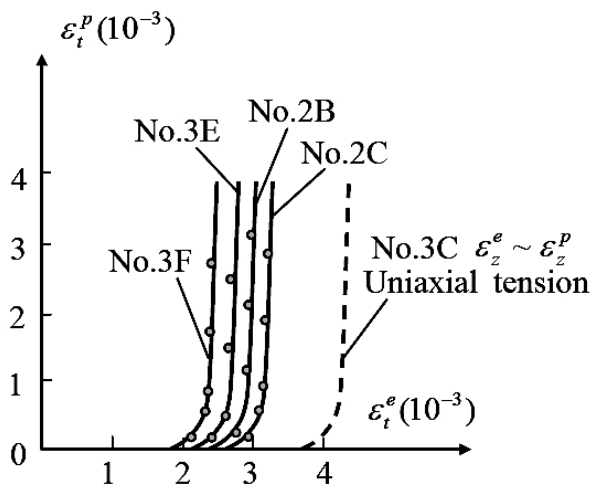

Fig. 6. $e-p$ curve from Fig. 4 .

stress-strain curve. These curves are shown in Figs. 3 and 4. In these figures, $\sigma_{z}$ is the axial stress and $\sigma_{t}$ is the transverse stress, while $\sigma_{z}=f\left(\sigma_{t}\right)$ is the relationship between transverse and axial stresses.

As it follows from Figs. 3 and $4, e-p$ curves can be plotted respectively for every curve, as shown in Figs. 5 and 6. And if unloading procedure is not considered, from Figs. 5 and 6 it can be seen that the patterns of all $e-p$ curves are nearly the same, i.e., any $e-p$ curve can be obtained by displacing another $e-p$ curve along the $\varepsilon^{e}$ axis. In the unloading procedure, $e-p$ curve will be parallel to axis $\varepsilon^{e}$, such as line $\overline{a b}$ in Fig. 5 . 
Another example is the triaxial test of Carrara marble at room temperature [14]. The stress-strain curve of this experiment is shown in Fig. 7, while the $e-p$ curve is shown ins Fig. 8. It can be seen from Fig. 8 that the patterns of the $e-p$ curves under confining pressures are quite similar.

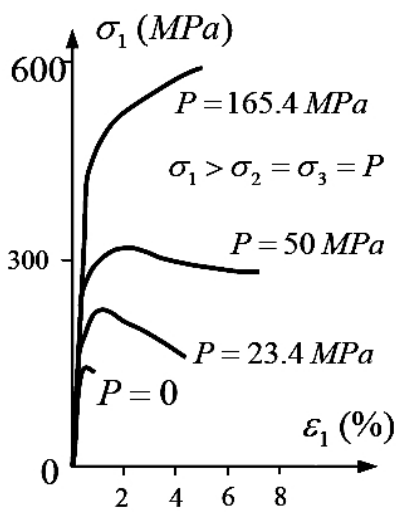

Fig. 7. Triaxial stress-strain curve of marble test [14].

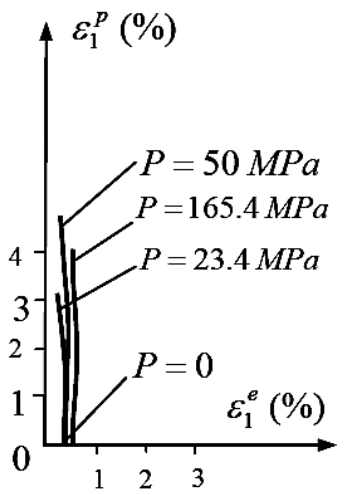

Fig. 8. $e-p$ curve of marble [14].

The characteristics of the $e-p$ curves of the isotropic, continuous, and homogenous materials have been generalized as the following preliminary relationship [12, 15]:

(1) Under simple loading, any $e-p$ curve of the principal strain can be obtained by the shifting any other $e-p$ curve of the principal strain along axis $\varepsilon^{e}$. That is to say, the increments of elastic and plastic strains after yield conditions follow the same rule under simple loading.

(2) If $\varepsilon^{p}=f\left(\varepsilon^{e}\right)$ of the $e-p$ curve of the principal strain under simple loading is taken as a standard, then the elastic $\varepsilon_{i j}^{e}$ and plastic $\varepsilon_{i j}^{p}$ parts of strain for any stress-strain state satisfy the following relation:

$$
\varepsilon_{i j}^{p}=f\left[\varepsilon_{i j}^{e}+L_{i j}\left(\varepsilon_{i j}^{e}, \alpha\right)\right] .
$$

The essence of $L_{i j}$ is shown in Fig. 9, while $\alpha$ is the parameter related to the loading history.

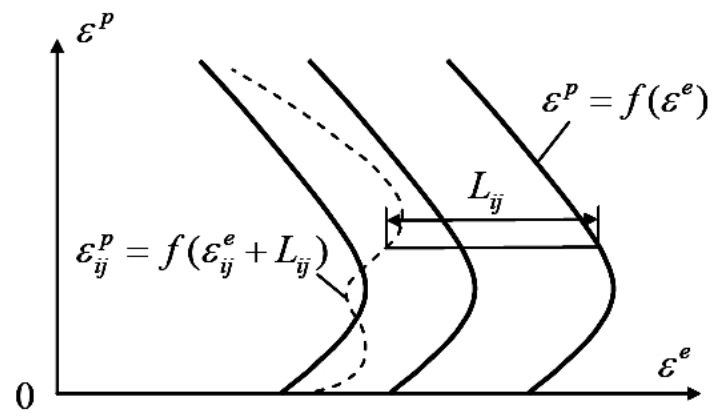

Fig. 9. Sketch map of $e-p$ curve.

Based on the single curve hypothesis proven by experiments under simple loading [16], it has been corroborated that the relationship between elastic and plastic strains mentioned above really holds for two kinds of stress-strain states [12]. 


\section{A New Strength Criterion and the Relationship between Strength and Yield}

Criteria. Consider the case of simple loading. According to the above relationship for the $e-p$ curves, $e-p$ curves of the maximum principal strains can be plotted as is shown in Fig. 10 for some stress-strain states. Assume that curve 1 is the $e-p$ curve of the uniaxial stress-strain state, while curve 2 is the $e-p$ curve of one stress-strain state under consideration, and $\varepsilon_{s}$ is the elastic limit strain of uniaxial stress-strain state. This an apparent indication that plastic strains are the same in failure points of all of stress-strain states. The plastic strain of failure point is assumed as $K^{p}$, which yield the following strength criterion [17]:

$$
\varepsilon_{i}^{p} \leq K^{p}, \quad i=1,2,3
$$

Parameter $\varepsilon_{i}^{p}$ in Eq. (2) is the plastic strain part of the principal strain.

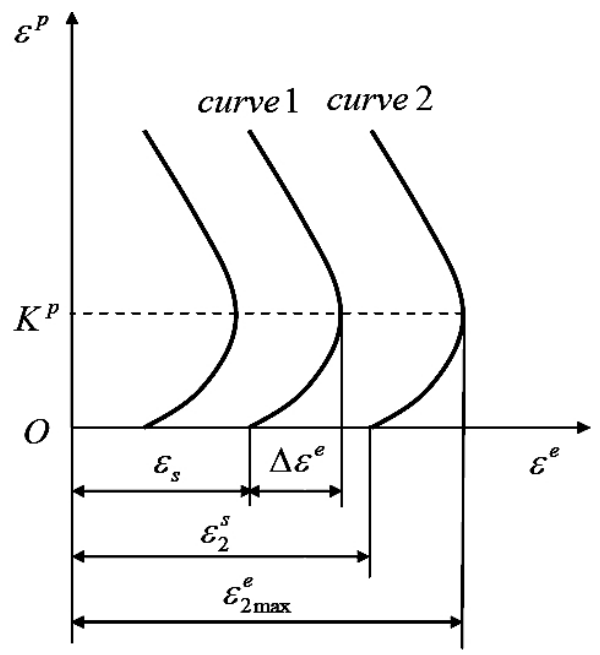

Fig. 10. The $e-p$ curves of the maximum principal strain under simple loading conditions.

Currently, strength criteria are basically expressed via the principal stress, which is convenient for applications, in contrast to the strength criterion of Eq. (2). Now, based on $e-p$ curve, we re-consider the strength criterion from the other standpoint.

From Fig. 10, we have

$$
\varepsilon_{2 \max }^{e}=\left[\sigma_{1}^{b}-\mu\left(\sigma_{2}^{b}+\sigma_{3}^{b}\right)\right] / E=\varepsilon_{2}^{s}+\Delta \varepsilon^{e}=\varepsilon_{2}^{s}+\left(\varepsilon_{b}^{e}-\varepsilon_{s}\right),
$$

where $\sigma_{i}^{b}(i=1,2,3)$ are three principal stresses of failure point of curve $2, \varepsilon_{2}^{s}$ is the elastic limit strain of the stress-strain state under consideration, and $\varepsilon_{b}^{e}$ is the elastic part of strain of failure point in the uniaxial stress-strain state (curve 1 ), $\Delta \varepsilon^{e}=\varepsilon_{b}^{e}-\varepsilon_{s}$.

We get

$$
\begin{gathered}
\varepsilon_{2}^{s}=\left[\sigma_{1}^{s}-\mu\left(\sigma_{2}^{s}+\sigma_{3}^{s}\right)\right] / E, \\
\varepsilon_{b}^{e}-\varepsilon_{s}=\left(\sigma_{b}-\sigma_{s}\right) / E
\end{gathered}
$$

where $\sigma_{i}^{s}(i=1,2,3)$ are three principal stresses of the yield point of curve $2, \sigma_{b}$ and $\sigma_{s}$ are the failure and yield stresses of the uniaxial stress-strain state, respectively. 
Substituting Eqs. (4) and (5) into Eq. (3) leads to

$$
\left[\sigma_{1}^{b}-\mu\left(\sigma_{2}^{b}+\sigma_{3}^{b}\right)\right]-\left[\sigma_{1}^{s}-\mu\left(\sigma_{2}^{s}+\sigma_{3}^{s}\right)\right]=\sigma_{b}-\sigma_{s} .
$$

If $\sigma_{1}^{s}-\mu\left(\sigma_{2}^{s}+\sigma_{3}^{s}\right)=\sigma_{s}$, Eq. (6) is

$$
\sigma_{1}^{b}-\mu\left(\sigma_{2}^{b}+\sigma_{3}^{b}\right)=\sigma_{b} .
$$

Equation (7) describes the maximum principal strain strength criterion. From the pattern of the $e-p$ curve, we know that $\sigma_{1}^{s}-\mu\left(\sigma_{2}^{s}+\sigma_{3}^{s}\right)$ is generally not equal to $\sigma_{s}$, i.e., $\varepsilon_{2}^{s}$ is generally not equal to $\varepsilon_{s}$ in Fig. 10. Therefore, Eq. (6) can be treated as modification of the maximum principal strain strength criterion.

Let $k=\sigma_{b}-\sigma_{s}, k$ is a material constant, then Eq. (6) can be written as

$$
\left[\sigma_{1}^{b}-\mu\left(\sigma_{2}^{b}+\sigma_{3}^{b}\right)\right]-\left[\sigma_{1}^{s}-\mu\left(\sigma_{2}^{s}+\sigma_{3}^{s}\right)\right]=k .
$$

Equation (8) is the new strength criterion expressed via the principal stress.

Equation (8) also controls a new yield criterion, since term $\left[\sigma_{1}^{b}-\mu\left(\sigma_{2}^{b}+\sigma_{3}^{b}\right)\right]$ of Eq. (8) is controlled by the stressed state of failure state, whereas $\left[\sigma_{1}^{s}-\mu\left(\sigma_{2}^{s}+\sigma_{3}^{s}\right)\right]$ term of Eq. (8) is contolled by that of the yield state. Thus, one of these two states is defined, while another one can been determined by Eq. (8), which, therefore, establishes the relationship between the strength and yield criteria.

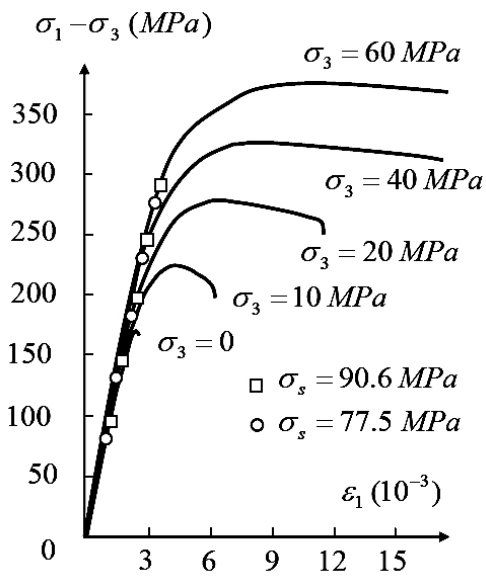

Fig. 11. Triaxial test of Fangshan marble.

Since it is easier to determine the strength limit than the yield stress through experiment, Eq. (8) will simplify development and formulation of the yield criterion.

3. An Application Example of the Relationship between Strength and Yield Criteria. Triaxial test of marble specimens [18] is an example to support the above relationship between the strength and yield criteria. Specimens were manifactured from marble was produced in Fangshan, Beijing (China). The experimental curves are given in Fig. 11, whereas $\sigma_{3}$ in Fig. 11 is the confining pressure $\left(\sigma_{2}=\sigma_{3}\right)$. Since the confining pressure remained unchanged during the tests, Eq. (8) can be reduced to

$$
\sigma_{1}^{b}-\sigma_{1}^{s}=\sigma_{b}-\sigma_{s} .
$$


Development of Strength and Yield Criteria ...

$\mathrm{T}$ a b 1 e 1

Yield Stress Calculated from Eq. (9)

\begin{tabular}{||c|c|c|c|c|c||}
\hline$\sigma_{3}, \mathrm{MPa}$ & 0 & 10 & 20 & 40 & 60 \\
\hline$\sigma_{1}^{b}-\sigma_{3}, \mathrm{MPa}$ & 170.43 & 225.22 & 277.87 & 325.65 & 374.35 \\
\hline$\sigma_{1}^{s}-\sigma_{3}\left(\sigma_{s}=77.5\right), \mathrm{MPa}$ & 77.50 & 132.29 & 184.94 & 232.72 & 281.42 \\
\hline$\sigma_{1}^{s}-\sigma_{3}\left(\sigma_{s}=90.6\right), \mathrm{MPa}$ & 90.60 & 145.39 & 198.04 & 245.82 & 294.52 \\
\hline
\end{tabular}

Here values $\sigma_{1}^{b}$ of each curve and $\sigma_{b}$ are easily derived from Fig. 11 and tabulated in Table 1, whereas assessment of the yield stress values of each curve is more problematic. We take two values of the uniaxial yield stress $\sigma_{s}: \sigma_{s}=77.5$ and $90.6 \mathrm{MPa}$, while $\sigma_{1}^{s}$ of each curve can be calculated via Eq. (9), as is shown in Table 1 and Fig. 11. In Fig. 11, circular points correspond to $\sigma_{s}=77.5 \mathrm{MPa}$, whereas square points correspond to $\sigma_{s}=$ $=90.6 \mathrm{MPa}$. Taking into account the discrete nature of the rock material tests, the yield stresses calculated via Eq. (9) are quite acceptable.

Conclusions. Plotting the $e-p$ curve implies a new vway to describe the deformation properties of materials. Based on the $e-p$ curve pattern in simple loading, we consider the respective strength and yield criteria. A new strength criterion is proposed, which can be treated as a modification of the maximum principal strain strength criterion. Since it establishes the relationship between strength and yield criterion, it may also be treated as a new yield criterion. Since the proposed criteria are derived for the case of simple loading, their applicability to complex loading cases needs further experimental verification.

\section{Резюме}

Представлено результати дослідження співвідношень між пружними і пластичними деформаціями. На основі результатів аналізу цих співвідношень запропоновано новий критерій міцності, який є модифікацією критерію максимальних головних деформацій. Оскільки запропонований підхід ув'язує критерії міцності і пластичної плинності, даний критерій можна трактувати як новий критерій пластичної плинності.

1. S. Patnaik and D. Hopkins, Strength of Materials: A New Unified Theory for the 21st Century, Butterworth-Heinemann, Oxford (2003).

2. M. H. Yu, Unified Strength Theory and Its Applications, Springer, Heidelberg-Berlin (2002).

3. X. He and B. Xing, "The ultimate tensile strength of coach peel self-piercing riveting joints," Strength Mater., 45, No. 3, 386-390 (2013).

4. V. A. Romashchenko, "Strength assessment for composite and metal-composite cylinders under pulse loading. Part 1. Rules of choosing various strength criteria for anisotropic material and comparative analysis of such criteria," Strength Mater., 44, No. 4, 376-387 (2012).

5. M. Huang and C. S. Man, "A generalized Hosford yield function for weakly-textured sheets of cubic metals," Int. J. Plasticity, 41, 97-123 (2013).

6. N. Iwata, T. Sasaki, R. Yoshinaka, et al., "Applicability of the multiple yield model for estimating the deformation of vertical rock walls during large-scale excavations," Int. J. Rock Mech. Min. Sci., 52, 171-180 (2012).

7. H. Jiang and Y. Xie, "A note on the Mohr-Coulomb and Drucker-Prager strength criteria," Mech. Res. Commun., 38, 309-314 (2011). 
8. D. Jang, C. T. Gross, and J. R. Greer, "Effects of size on the strength and deformation mechanism in Zr-based metallic glasses," Int. J. Plasticity, 27, 858-867 (2011).

9. S. Turgeman, and B. Guessab, "Lower bound of effective yield strength domain for random heterogeneous," Mech. Res. Commun., 38, 181-185 (2011).

10. M. You, "True-triaxial strength criteria for rock," Int. J. Rock Mech. Min. Sci., 46, 115-127 (2009).

11. A. R. Zamiri and F. Pourboghrat, "A novel yield function for single crystals based on combined constraints optimization," Int. J. Plasticity, 26, 731-746 (2010).

12. Y. Li, Z. D. Chen, and W. S. Zhu, "Research on relationship between elastic and plastic deformation of materials," Rock Soil Mech., 9, No. 3, 41-50 (1988).

13. J. M. Lessells and C. W. MacGregor, "Combined stress experiments on a nickelchrome-molybdenum steel," J. Franklin Inst., 230, 163-181 (1940).

14. V. Karman, "Festigkeitsversuche unter allseitigem Druck," Z. Ver. deutsch. Ing., 55, 1749-1757 (1911).

15. Y. Li, Introduction to Plasticity Mechanics [in Chinese], Science Press, Beijing (2008).

16. L. M. Kachanov, Foundations of the Theory of Plasticity, North-Holland Publication Company, Amsterdam-London (1971).

17. Y. Li, "New strength criterion based on relationship between elastic and plastic strains," Adv. Mater. Res., 146-147, 166-169 (2011).

18. F. Wang, X. Yang, and B. Yao, "Triaxial test on Fangshan marble," Earthquake, No. 5, 15-19 (1983). 